\title{
Role of Positron Emission Tomography (PET) in the Setting of Biochemically Recurrent Prostate Cancer
}

Chris McClinton, Sumit Sood and Xinglei Shen*

Department of Radiation Oncology, University of Kansas Cancer Center, Kansas City, USA

\begin{abstract}
Prostate cancer is the most common solid malignancy among men in the Western world. Of the $50 \%$ of patients with localized prostate cancer who elect to undergo radical prostatectomy, up to $60 \%$ will experience recurrence of disease. Salvage radiotherapy is the standard treatment for biochemically recurrent prostate cancer but rates of success in terms of long-term biochemical control remain suboptimal. Functional imaging may potentially improve salvage radiotherapy via detection of disease foci which would otherwise be missed by conventional imaging modalities. Herein we review the most commonly employed PET radiotracers for prostate cancer (11C-choline, 18F-choline, and 11C-acetate) with particular attention on their ability to identify foci of recurrent disease as well as their utility as a guide for radiotherapy.
\end{abstract}

Keywords: Prostate cancer; Positron emission tomography (PET); Choline; Acetate; Radiation; Radiotherapy

\section{Introduction}

\section{Challenges in salvage radiotherapy after prostatectomy}

Prostate cancer is the most common solid malignancy in American men with over 22,000 new cases expected to be diagnosed in 2015 [1]. Definitive treatments for localized prostate cancer include radical prostatectomy and radiation therapy. Approximately half of patients with localized prostate cancer elect to undergo radical prostatectomy [2]. Recurrence of disease after prostatectomy is common-occurring in up to $60 \%$ of patients with high risk features [3-5]. In these patients, salvage radiation therapy (SRT) prolongs survival and is indicated as a potentially curative treatment [6]. SRT consists of fractionated radiation therapy directed to the regions at highest risk of harboring residual prostate cancer. Typical prescription dose ranges from $60-70$ Gy in 1.8-2.0 Gy daily fractions. Current guidelines from the EORTC and RTOG target the prostate bed, with or without the seminal vesicles, but do not include the pelvic lymph nodes. Biochemical control rates with this approach range from $20-70 \%$ and largely depend upon prognostic factors including high pre-SRT PSA, rapid PSA doubling time (PSA-DT), negative surgical margins, high Gleason score, extracapsular extension of disease, and seminal vesicle invasion [7]. Due to the relatively suboptimal results, active investigations are ongoing in attempt to improve the efficacy of SRT. With this goal, the RTOG has investigated the addition of androgen deprivation therapy and chemotherapy to post-operative radiation as well as extension of the standard prostate bed treatment field to include the pelvic lymphatics $[8,9]$. A key opportunity to improve the outcome of postprostatectomy radiation therapy could be enhanced detection of the location of recurrent cancer to improve patient selection and target volume delineation:

1. Detection of disease in the prostate bed may allow focal dose escalation to the site of recurrence. Dose escalation in the intact prostate setting is associated with improved biochemical control and retrospective evidence suggests that this may also apply to SRT $[10,11]$.

2. Detection of nodal metastatic cancer would alter field design to encompass pelvic lymphatics and possibly direct delivery of a boost dose to involved nodes. The addition of pelvic radiation therapy has been reported to improve survival in patients with node-positive cancer $[12,13]$.

3. Detection of distant metastatic disease prior to SRT may spare patients from unnecessary treatment and attendant toxicities. Conventional imaging modalities including computed tomography (CT), bone scan, and magnetic resonance imaging (MRI) are insufficient in identifying recurrent disease after prostatectomy $[14,15]$. CT and MRI have also demonstrated a poor sensitivity for detecting lymph node involvement with prostate cancer [16]. Recently, there has been increased interest in functional PET imaging to better characterize tumor burden in recurrent prostate cancer. PET presents itself as an attractive supplemental imaging modality in its potential ability to identify metabolically active tumors in comparison to conventional modalities which detect only anatomical deformity [17,18]. Initial studies have reported promising results with radiolabeled choline PETCT for detection of recurrent disease [19-23]. This review focuses on the relevant data regarding the utility of lipid metabolism based PET $\left({ }^{11} \mathrm{C}\right.$-choline, ${ }^{18} \mathrm{~F}$-choline, and ${ }^{11} \mathrm{C}$-acetate) as it pertains to management of biochemically recurrent prostate cancer (Table1) from the standpoint of a radiation oncologist.

\section{Functional imaging in prostate cancer}

FDG-PET is of limited utility in prostate cancer because of both biologic and anatomical characteristics. Prostate adenocarcinomas are a biologically heterogeneous group of tumors with variable FDG- uptake. Majority comprise of slow-growing and well-differentiated tumors, and a minority include poorly differentiated cancers [24,25]. Well differentiated prostate cancer cells tend to express much lower levels of cellular membrane glucose transporters than do poorly differentiated

*Corresponding author: Xinglei Shen, Department of Radiation Oncology, University of Kansas Cancer Center, Kansas City, USA, Tel: +913 588-5310; Fax: +913 588-3663; E-mail: xshen@kumc.edu

Received March 14, 2016; Accepted April 09, 2016; Published April 15, 2016

Citation: McClinton C, Sood S, Shen X (2016) Role of Positron Emission Tomography (PET) in the Setting of Biochemically Recurrent Prostate Cancer. J Nucl Med Radiat Ther 7: 285. doi:10.4172/2155-9619.1000285

Copyright: (c) 2016 McClinton C, et al. This is an open-access article distributed under the terms of the Creative Commons Attribution License, which permits unrestricted use, distribution, and reproduction in any medium, provided the original author and source are credited. 


\begin{tabular}{|c|c|c|c|}
\hline & & Advantages & Disadvantages \\
\hline \multirow{3}{*}{$\begin{array}{l}\text { Conventional } \\
\text { Imaging } \\
\text { Modalities }\end{array}$} & CT & $\begin{array}{l}\text { Readily available } \\
\text { - Good resolution } \\
\text { of structural } \\
\text { abnormalities in } \\
\text { soft tissue and } \\
\text { bone }\end{array}$ & $\begin{array}{l}\text { Poor detection } \\
\text { of small lymph } \\
\text { node and bone } \\
\text { metastases }\end{array}$ \\
\hline & MRI & $\begin{array}{l}\text { Readily available } \\
\text { - Excellent } \\
\text { resolution } \\
\text { of structural } \\
\text { abnormalities in } \\
\text { soft tissue }\end{array}$ & $\begin{array}{l}\text { Poor detection } \\
\text { of small lymph } \\
\text { node and bone } \\
\text { metastases }\end{array}$ \\
\hline & $\begin{array}{l}\text { Bone } \\
\text { scan }\end{array}$ & $\begin{array}{l}\text { - Readily available } \\
\text { - Good detection of } \\
\text { bone metastases }\end{array}$ & $\begin{array}{l}\text { - Detection limited to } \\
\text { bone metastases }\end{array}$ \\
\hline \multirow{2}{*}{$\begin{array}{l}\text { Functional } \\
\text { Imaging } \\
\text { Modalities }\end{array}$} & $\begin{array}{l}\text { FDG } \\
\text { PET }\end{array}$ & - Readily available & $\begin{array}{l}\text { Poor uptake and } \\
\text { detection of low/ } \\
\text { intermediate grade } \\
\text { disease } \\
\text { - Urinary excretion } \\
\text { of FDG interferes } \\
\text { with visualization of } \\
\text { pelvic anatomy }\end{array}$ \\
\hline & $\begin{array}{l}\text { Choline/ } \\
\text { acetate } \\
\text { PET }\end{array}$ & $\begin{array}{l}\text { Good detection } \\
\text { of small lymph } \\
\text { node and bone } \\
\text { metastases } \\
\text { - Low urinary } \\
\text { excretion } \\
\text { allows for better } \\
\text { visualization of } \\
\text { pelvic anatomy }\end{array}$ & $\begin{array}{l}\text { - Limited availability } \\
\text { Potential out-of- } \\
\text { pocket cost for } \\
\text { patients }\end{array}$ \\
\hline
\end{tabular}

Table 1: Advantages and disadvantages of conventional and functional imaging modalities in the setting of biochemically recurrent prostate cancer.

prostate cancer cells and this may explain why FDG uptake seems to correlate with degree of differentiation with well differentiated cells exhibiting poor FDG uptake and poorly differentiated cells exhibiting high FDG uptake [26,27]. From an anatomic perspective, visualization of pelvic structures is also obscured by urinary excretion of FDG and accumulation in the bladder [28]. Specifically, ${ }^{111} \mathrm{In}$ capromab (Prostascint) was the first radiolabeled monoclonal antibody produced for targeting prostate specific membrane antigen (PSMA) [29]. Despite promising early results, it was ultimately found to have poor clinical efficacy due to requiring the antibody to bind to an intracellular receptor within the prostate cancer cell. This condition limited the radionuclide's affinity to nonviable cells with damaged cellular membranes and led to relatively poor sensitivity (49\%) and specificity $(71 \%)$ in the salvage setting [30,31]. Recently, radiolabeled choline and acetate PET have emerged as potential imaging modalities to identify recurrent prostate cancer. These tracers exploit malignancyinduced cellular membrane lipogenesis. Prostate cancer has been associated with an overexpression of fatty acid synthase and, in turn, an increase in fatty acid synthesis $[32,33]$. As precursor molecules involved in lipogenesis, radiolabeled acetate and choline have demonstrated high rates of uptake into prostate cancer cells [34-36]. Additionally, unlike FDG, radiolabeled acetate and choline tend to exhibit little urinary excretion thereby limiting interference with visualization of pelvic structures that would otherwise be obscured due to accumulation of radiotracer in the bladder [37]. Choline and acetate molecules have been tested with both ${ }^{11} \mathrm{C}$ and ${ }^{18} \mathrm{~F}$ isotopes and the most commonly used products are ${ }^{11} \mathrm{C}$-choline, ${ }^{18} \mathrm{~F}$-choline, and ${ }^{11} \mathrm{C}$-acetate. The utility of ${ }^{11} \mathrm{C}$-choline PET for identification of prostate cancer was first described by Hara et al. in 1998 and ${ }^{18} \mathrm{~F}$-choline was subsequently reported to have increased uptake in prostate cancer cells in 2001 [38,39]. Oyama et al. described the use of ${ }^{11} \mathrm{C}$-acetate $\mathrm{PET}$ for identification of prostate cancer in 2002 [40]. Though ${ }^{18} \mathrm{~F}$-choline has a clinically relevant urinary excretion of 7.5\%, the biodistribution of the three molecules is otherwise similar $[41,42]$. However, the molecules do differ significantly in terms of half-life which, at approximately 20 minutes for the ${ }^{11} \mathrm{C}$ isotope and 110 minutes for the ${ }^{18} \mathrm{~F}$ isotope, tends to limit use of ${ }^{11} \mathrm{C}$-choline and ${ }^{11} \mathrm{C}$-acetate to centers with an on-site cyclotron. Furthermore, hypoxia may have some bearing on uptake of choline and acetate in prostate cancer cells as in vitro studies have reported preferential uptake of choline in aerobic conditions and preferential uptake of acetate in hypoxic conditions [43]. An intraindividual comparison of ${ }^{11} \mathrm{C}$-choline and ${ }^{11} \mathrm{C}$-acetate by Kotzerke et al. found no difference between the two radiotracers in detection of prostate cancer metastases [37]. However, ${ }^{11} \mathrm{C}$-choline, ${ }^{18} \mathrm{~F}$-choline, and ${ }^{11} \mathrm{C}$-acetate have not, as of yet, been compared in the setting of a prospective, randomized clinical trial. While all three have been heavily adopted in Europe, their use in the United States was relatively limited until 2013 when the FDA approved the use of ${ }^{11} \mathrm{C}$-choline PET for the detection of primary, recurrent, and metastatic prostate cancer [44].

\section{Imaging properties in the post-prostatectomy setting by anatomic location}

Overall sensitivity and specificity: Numerous individual series have reported the performance characteristics of ${ }^{11} \mathrm{C}$-acetate, ${ }^{11} \mathrm{C}$-choline and ${ }^{18} \mathrm{~F}$-choline PET/CT. Fanti et al. reported a meta-analysis of 29 relevant studies with 2,686 cases of ${ }^{11} \mathrm{C}$-choline. Heterogeneity was large, and confirmation of study findings was a mixture of histologic confirmation and clinical interpretation. Median PSA ranged from 0.5-6.9 $\mathrm{ng} / \mathrm{mL}$. The majority of studies reported median PSA at time of scan around $2 \mathrm{ng} / \mathrm{mL}$. In general, scan positivity was $62 \%$. Pooled sensitivity was $89 \%$ and pooled specificity was $89 \%$ [45]. Other meta-analyses have reported similar results with ${ }^{11} \mathrm{C}$-acetate PET/CT $[46,47]$.

Prostate bed: Functional PET/CT may be used to identify regions of residual tumor in the prostate bed which are not readily seen on conventional CT. Fanti et al. performed a systemic review and metaanalysis of studies evaluating the ${ }^{11} \mathrm{C}$-choline PET/CT in detection of prostate bed recurrence [45]. Data from 11 studies reported an overall detection rate of $27 \%$. Pooled sensitivity was $61 \%$ and specificity was 97\%. However, a particular care must be applied to the interpretation of this data, as there was wide heterogeneity and variability in the data reported from included trials. Additionally, most of the reports were noted for biopsy proven local relapse only, where the size of the recurrence is larger and the region of recurrent may be visualized by conventional imaging [48-50]. Results of choline PET/CT are less encouraging when limited to earlier recurrence, where salvage radiation therapy would be expected to be more effective. In this population, MRI appears to be a superior modality for detection of local recurrence. Vees et al. explored the use of functional imaging at low PSA level in a cohort of 22 patients with early biochemical recurrence (median PSA $0.33 \mathrm{ng} /$ $\mathrm{mL}$ ) using either ${ }^{18} \mathrm{~F}$-choline or ${ }^{11} \mathrm{C}$-acetate PET/CT [51]. Recurrent disease was identified on PET/CT in approximately 11 of 22 (50\%) patients. Interestingly, in the same cohort, endorectal MRI was positive in 15 of $18(83 \%)$ patients. After radiation therapy, PSA decreased in 7 of $10(70 \%)$ patients with local disease identified by PET/CT and in 11 of 16 (69\%) with disease identified by MRI (Figure1). Panebianco et al. also explored the use of ${ }^{18} \mathrm{~F}$-choline PET/CT in 84 patients with local recurrence prior to salvage radiation therapy [48]. In this study, 
Citation: McClinton C, Sood S, Shen X (2016) Role of Positron Emission Tomography (PET) in the Setting of Biochemically Recurrent Prostate Cancer. J Nucl Med Radiat Ther 7: 285. doi:10.4172/2155-9619.1000285

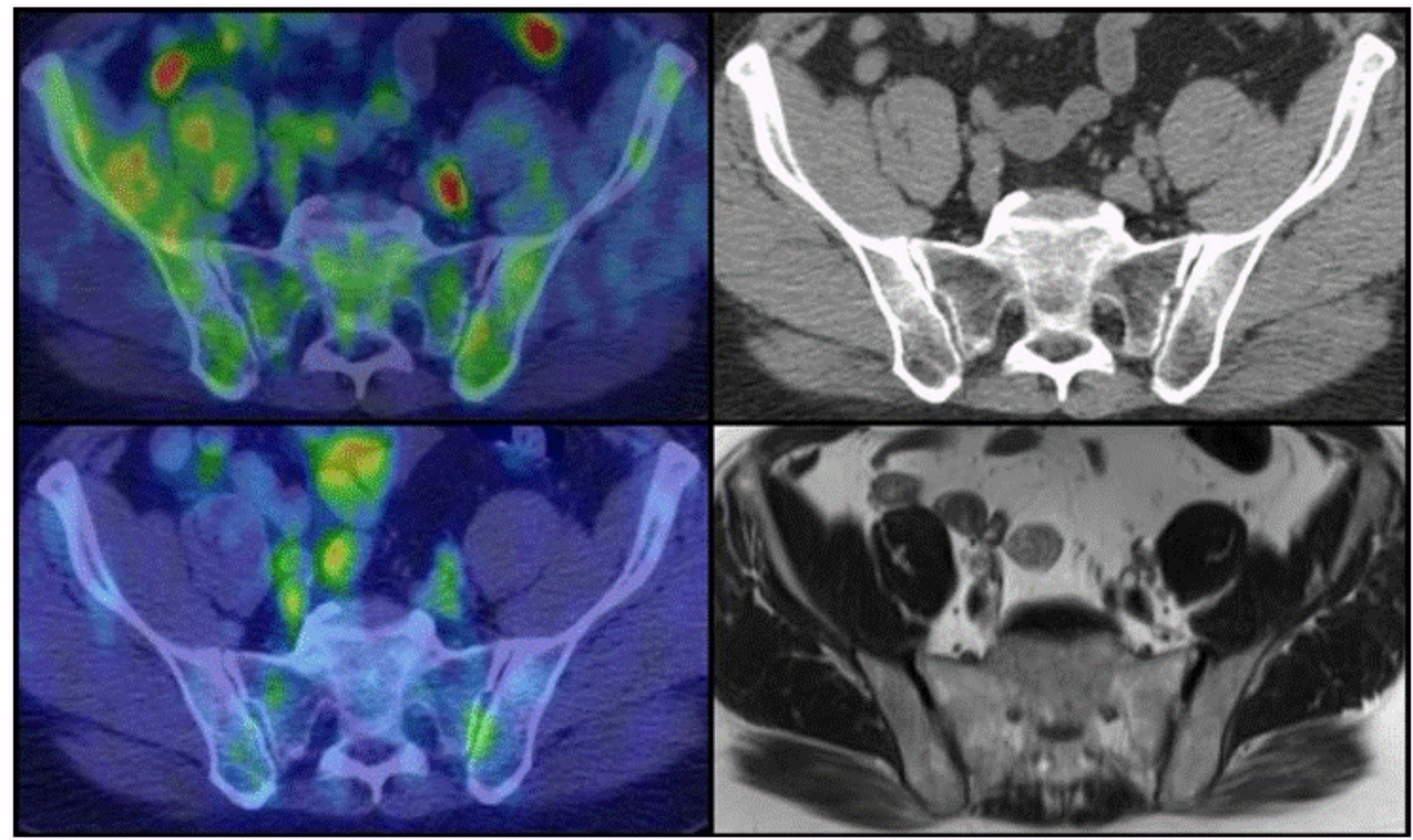

Figure 1: Representative images of prostate cancer nodal metastasis at the confluence of the left external and internal iliac vessels as demonstrated by various imaging modalities: ${ }^{11} \mathrm{C}$-acetate PET (top left), CT (top right), FDG PET (bottom left), T2 weighted MRI (bottom right). Scans were obtained from the same patient over the course of 2 months and no treatment was performed between scans.

patients were divided in to an early favorable group (PSA $0.8-1.4 \mathrm{ng} /$ $\mathrm{mL}$, lesion size 5-7 $\mathrm{mm}$ ) and unfavorable group (PSA $1.3-2.5 \mathrm{ng} / \mathrm{mL}$, lesion size $7.6-19.4 \mathrm{~mm})$. For the favorable group, the sensitivity and specificity and accuracy were $62 \%, 50 \%$, and $60 \%$. In the same study, MRI performed much better-particularly in the favorable group-with sensitivity of $92 \%$, specificity of $75 \%$ and accuracy of $89 \%$.

Lymph nodes: The particular benefit of PET/CT over conventional imaging is its ability to detect regional recurrence in lymph nodesan area where conventional imaging modalities perform poorly [45]. Detection of regional recurrence can influence radiation field design to include the pelvis over the standard prostate bed radiation field, and allow for focal dose escalation to involved lymph nodes.

Multiple studies have reported the diagnostic accuracy of choline PET in detecting lymph node metastases, verified with histologic confirmation. Meta-analysis from Fanti et al. reported an overall detection rate of $36 \%$, but did not performed pooled sensitivity and specificity due to the small number of studies which reported lymph node specific sensitivity and specificity [45]. A separate meta-analysis by Mohsen et al. reported sensitivity and specificity of $81.5 \%$ and $94.4 \%$ for detection of regional lymph nodes [47]. This report must be interpreted with caution due to the small number or studies reporting lymph node specific data. A particular note should be made of surgical series in this population. Scattoni et al. performed salvage lymph node dissection on 25 men with positive ${ }^{11} \mathrm{C}$-choline $\mathrm{PET} / \mathrm{CT}$ after biochemical recurrence. They reported a per lesion sensitivity of $64 \%$ and specificity of $90 \%$ with PPV and NPV of $86 \%$ and $72 \%$, respectively. Husarik et al. reported results of 23 patients who had lymph node metastases. Of the 7 patients who underwent salvage lymphadenectomy, 18 of 20 lymph nodes identified were positive on PET/CT. Two of 7 patients had additional lymph nodes identified on PET/CT. Schilling et al. also reported on 10 patients who underwent salvage lymphadenectomy for positive ${ }^{11} \mathrm{C}$-choline PET/CT. Seven of 10 patients had positive lymph nodes confirmed by histology. Passoni et al. reported an evocative series of 46 patients with solitary lymph node metastasis on ${ }^{11} \mathrm{C}$-Choline PET/ CT who underwent salvage lymph node dissection [52]. Thirty-eight of $46(83 \%)$ cases had histologic confirmation of lymph node metastasis. Histologic confirmation of the solitary lymph node noted on the scan was identified in only $65 \%$ of cases. Additional lymph nodes were identified nearby or elsewhere in the pelvis in $59 \%$ of cases. True histologic confirmation of a single lymph node was observed in only $24 \%$ of cases. For the radiation oncologist, finding of positive lymph node on functional PET/CT may be considered as an indicator of nodal metastases, but there is high likelihood of additional metastatic nodes in the pelvis.

Bone metastases: The performance of functional PET/CT in bone metastases also demonstrates promising results. Based on metaanalysis of ${ }^{11} \mathrm{C}$-choline from Fanti et al., the detection rate of bone metastases is $25 \%$ [45]. Pooled analyses were not performed due to very high heterogeneity.

Comparison between ${ }^{18} \mathrm{~F}$-choline and ${ }^{11} \mathrm{C}$-choline to standard $\mathrm{Tc}$ bone scan are favorable. Wondergem et al. performed a meta-analysis of studies evaluating ${ }^{18} \mathrm{~F}$-choline, ${ }^{11} \mathrm{C}$-choline, and ${ }^{18} \mathrm{~F}$-fluoride bone scan [53]. Per lesion pooled analysis for the choline studies were $84 \%$ sensitivity and $91 \%$ specificity, which was comparable to ${ }^{18} \mathrm{~F}$-fluoride scan, and better than historical reports of bone scan. 
${ }^{11} \mathrm{C}$-choline may have additional utility beyond standard Tc-bone scan. Picchio et al. reported a comparison of ${ }^{11} \mathrm{C}$-choline PET/CT and 99Tc-bone scan in a population with high risk recurrent prostate cancer [54]. Median PSA in this population was $2.4 \mathrm{ng} / \mathrm{mL}$. Bone metastases were found in $31 \%$ of cases by ${ }^{11} \mathrm{C}$-choline and $24 \%$ of cases by bone scan. Diagnostic accuracy was $95 \%$ by ${ }^{11} \mathrm{C}$-choline and $83 \%$ by bone scan. A challenge of bone scan interpretation was that equivocal results were noted in $27 \%$ of bone scans. If all equivocal scans on bone scan were considered to be positive, sensitivity of bone scan was better with a rate of $100 \%$ as compared to $89 \%$ for ${ }^{11} \mathrm{C}$-choline. Fuccio et al. also reported a series of 123 consecutive patients with biochemical recurrence of prostate cancer and negative Tc bone scan [55]. Additional bone metastases were identified in 18 of 123 (14.6\%) patients. In general, functional PET/CT appears to perform at least as well as conventional bone scan. There may be a small additional ability to detect metastases using PET/CT, but further investigation is warranted.

\section{Predictive factors for pet positivity}

A recent meta-analysis by Evangelista et al., which included 19 studies and 1555 patients and evaluated the role of choline PET in restaging of prostate cancer patients, demonstrated a pooled sensitivity of $85.6 \%$ and specificity of $92.6 \%$ for all subsites [56]. However, not all studies evaluating the role of $\mathrm{PET} / \mathrm{CT}$ in re-staging recurrent prostate cancer patients yield similar positive results.

The accuracy and utility of PET/CT in prostate cancer seems to be influenced by several variables including PSA value, PSA-DT, and PSA velocity $[19,20,54,57-59]$. One of the principal concerns in choline-PET remains its predictive value, particularly in the early recurrence state with relatively low PSA values where radiotherapy may have the largest impact. Studies have already demonstrated that the overall detection of recurrent disease of ${ }^{18} \mathrm{~F}$-choline PET increases with higher PSA values $[60,61]$. However, higher PSA values are also correlated with higher risk of metastatic disease in which local treatments such as radiotherapy would not offer curable intent. Thus, studies performed have attempted to identify a "trigger point" PSA value where utilization of molecular imaging techniques in prostate cancer may prove the most beneficial. Studies by de Jong and Richter have demonstrated higher rates of recurrent PET/CT detection with PSA values $>5 \mathrm{ng} / \mathrm{mL}$ ranging from $70 \%$ to $100 \%$ [19-62]. Similarly, data from Schillaci et al. has demonstrated a detection rate of $87 \%$ with PSA values $>4 \mathrm{ng} / \mathrm{Ml}$ [63]. Recently, however, Giovacchini et al. reported a cut off value much lower at $1.4 \mathrm{ng} / \mathrm{mL}$, in the range where SRT may potentially impact bPFS. The authors reported a $73 \%$ sensitivity rate and $72 \%$ specificity rate with ${ }^{11} \mathrm{C}$-choline $\mathrm{PET} / \mathrm{CT}$ when PSA values are $>1.4 \mathrm{ng} / \mathrm{mL}$. Conversely, with PSA values $<1.4 \mathrm{ng} / \mathrm{mL}$ PET/CT was positive in only $24 \%$ of patients [20]. Furthermore, Krause et al. supported data from Giovachini in confirming a detection rate of $36 \%$ by ${ }^{11} \mathrm{C}$-choline PET/ CT for PSA values $<1 \mathrm{ng} / \mathrm{mL}$ [59]. Other factors that have demonstrated the potential ability to influence the detection rate of PET/CT for recurrent prostate cancer include PSA-DT and PSA velocity. Giovacchini et al. and Castellucci et al. have demonstrated higher rates of choline detection rates with PSA-DT $<2$ or 3 months relative to PSA-DT $>6$ months, ranging from $60 \%$ to $80 \%$ and $40-60 \%$, respectively [57,58-64]. Furthermore, PSA velocity $>1 \mathrm{ng} / \mathrm{mL} /$ year in biochemically recurrent prostate cancer has been demonstrated to discriminate between obtaining positive vs. negative ${ }^{11} \mathrm{C}$-choline PET/CT detection rates [57].

\section{Outcomes of pet-directed radiotherapy}

Surgical series have provided proof of principle for functional PET directed therapy. Winter et al. reported a series of 13 patients with biochemical recurrence who underwent salvage lymphadenectomy for nodes detected on functional PET [65]. Eleven patients had confirmed lymph node metastases and, of them, 91\% (10/11) had a decrease in PSA. Of these, 3 had long-term remission (31-83 months) without additional therapy. Rigatti reported a series of 72 patients treated with salvage lymphadenectomy and no adjuvant therapy [66]. Biochemical complete response was noted in $57 \%$ and 5 year freedom from biochemical recurrence was $35 \%$. Karnes et al. reported similar results in a U.S. series of 52 men with 3 year biochemical recurrence free survival of $46 \%$ [67]. Souvatzoglou et al. studied the influence of ${ }^{11} \mathrm{C}$-choline PET/CT in defining the extent of the planning target volume (PTV) in 37 men with biochemically recurrent prostate cancer [68]. Median PSA was $0.5 \mathrm{ng} / \mathrm{mL}$ at the time of the scan. The standard treatment volume (prostate bed) was expanded to include PET-positive foci adjacent to the prostate bed and these sites were also boosted to a total dose of 64 Gy. In patients with PET-positive pelvic lymph nodes, the treatment field was expanded to include the pelvic lymphatics ( $45 \mathrm{~Gy}$ ) with a boost dose delivered to positive lymph nodes (54Gy). PET/CT resulted in extension of the PTV to involve pelvic lymphatics in $13 \%(5 / 37)$ and was used for directed prostate bed boost in $19 \%$ (7/37). At the end of follow up (median 51.2 months), $56 \%$ of men had PSA $<0.2 \mathrm{ng} / \mathrm{mL}$. Of the 10 men with a positive PET scan who underwent radiotherapy, $50 \%(5 / 10)$ had PSA $<0.2 \mathrm{ng} / \mathrm{mL}$ at the end of follow up. Grade III rectal toxicity occurred at a rate of $40 \%$ in the group receiving PET-directed therapy as compared to $25 \%$ in those receiving standard radiotherapy. No cases of grade IV toxicity were recorded. Wurschmidt et al. reported their experience with using ${ }^{18} \mathrm{~F}$-fluoroethylcholine (FEC) PET as a guide for dose escalation to sites of disease in high risk primary $(n=7)$ or recurrent $(n=19)$ prostate cancer [69]. Of the 26 patients who underwent FEC PET imaging, 20 were found to have lymph node involvement. Pelvic lymphatics were treated to 45-50.4 Gy in 1.8 Gy fractions and a boost dose (amount unspecified) was delivered to lymphatic sites with positive FEC uptake. At 28 months, biochemical control was reported in $83 \%$ of patients treated for primary disease and $49 \%$ of patients treated for recurrent disease. No grade III toxicity was reported though there was one case of grade IV urinary toxicity in a patient who had been previously treated with TURP and seed brachytherapy. A similar study conducted by Picchio et al. examined the utility of ${ }^{11} \mathrm{C}$-choline PET-directed radiotherapy in 83 patients with nodal recurrence of prostate cancer [70]. Helical tomotherapy was employed with a mean dose of $52 \mathrm{~Gy}$ to all pelvic lymphatics and PET-positive lymph nodes were boosted to a mean total dose of $65 \mathrm{~Gy}$. Complete and partial biochemical responses were observed after $70.2 \%$ and $12.8 \%$ of treatments, respectively. Two cases of acute grade III genitourinary toxicity were reported. No cases of grade III gastrointestinal or rectal toxicity occurred. A subgroup of 47 patients underwent follow-up PET/CT and a complete or partial radiographic response to treatment was recorded in 42 patients (89.4\%). Casamassima et al. reported the results of choline PET-directed radiotherapy in 25 patients with nodal recurrence of prostate cancer [71]. Fifteen patients received SBRT to PET-positive abdominopelvic lymph nodes to a total dose of $30 \mathrm{~Gy}$ in 3 fractions. Seven patients received conventionally-fractionated radiotherapy of 50 Gy in 25 fractions delivered to pelvic lymphatics and a hypofractionated boost of $24 \mathrm{~Gy}$ in 3 fractions to positive lymph nodes. Three patients received SBRT to $30 \mathrm{~Gy}$ in 3 fractions to sites of distant metastases. No cases of grade II or greater toxicity were observed. At 3 years, overall survival, disease free survival, and local control rates were $92 \%, 17 \%$, and $90 \%$, respectively. Of note, thirteen patients achieved long term biochemical control and were deemed to have no evidence of disease at that time of 
publication.

In the setting of oligometastatic prostate cancer, Schick et al. reported their results of treatment with a combination of androgen deprivation therapy and choline PET-directed radiotherapy [72]. Of the 50 patients included in the study, 33 were found to have disease limited to regional or distant lymph nodes and 17 had visceral and/or osseous metastatic disease. All patients had fewer than 5 lesions on ${ }^{18} \mathrm{~F}$ or ${ }^{11} \mathrm{C}$-choline PET. For patients with pelvic nodal disease, radiotherapy consisted of $50.4 \mathrm{~Gy}$ in 28 fractions to pelvic lymphatics with boost to a median total dose of 65 Gy directed to PET-positive nodes. Distant disease sites were treated with SBRT using 28-36Gy in 5-6 fractions. No cases of grade III or IV toxicity were reported. At a median follow up of 31 months, overall survival and biochemical relapse free survival rates were $92 \%$ and $54.5 \%$, respectively. At our institution, we have used ${ }^{11} \mathrm{C}$-acetate PET imaging in patients with rising PSA around $1.0 \mathrm{ng} /$ $\mathrm{mL}$ or higher. In patients with positive lymph nodes, we have typically treated the pelvis to $50 \mathrm{~Gy}$ with sequential boost to the prostate bed and gross nodes to 60-66 Gy depending on nearby bowel tolerance. We have typically administered treatment with either short term or long term androgen deprivation therapy, given the proven benefit of ADT in men with node positive prostate cancer.

\section{Conclusion}

Lipid metabolism based PET appears to be a useful imaging modality in the setting of biochemically recurrent prostate cancer in that it allows for improved detection of foci of disease which may otherwise be missed by conventional imaging. PET offers better accuracy in identifying sites of lymph node and bone metastases compared to conventional modalities, but it should be noted that conventional imaging (specifically MRI) appears to provide better ability to detect recurrence in the prostate bed. At the present, functional PET/CT serves as a complement rather than an alternative to conventional imaging until other issues have been addressed. One critical factor remains the "trigger" PSA value point for ordering functional PET imagingparticularly in the early recurrent state where salvage radiotherapy may provide the largest benefit. Absolute PSA, PSA-DT, and PSA velocity have demonstrated the ability to influence the diagnostic accuracy of PET in the salvage setting but further research is needed to determine how these parameters should be applied to assess the utility of PET imaging on a patient-by-patient basis. In review of the available literature, we suggest a PSA cut off of $1.0 \mathrm{ng} / \mathrm{mL}$ or fast doubling time as triggers to obtain function imaging in selected patients. Another remaining question is the clinical application of PET derived treatment planning in prostate cancer. Although several published data exist and seem to be encouraging, PET derived treatment planning in recurrent prostate cancer remains investigational and prospective randomized clinical trials incorporating PET into the detection algorithm are needed to better define the role of PET is pertains to salvage radiation planning. This question is being addressed by the GETUG which is currently conducting a phase II clinical trial entitled "OLIGOPELVIS" which employs ${ }^{18} \mathrm{~F}$-choline directed therapy to assess the impact of functional PET compared to historical control [73]. This study will treat patients with 1-5 pelvic oligometastases to $54 \mathrm{~Gy}$ to the pelvis with concomitant boost of 66 Gy to the lymph nodes with 6 months ADT. Additional considerations for the role of functional PET/CT in the management of recurrent prostate cancer include cost and availability. Although ${ }^{11} \mathrm{C}$-choline PET/CT is approved by the FDA, adoption in the United States is limited and some private insurance carriers may not cover this scanning modality. Nonetheless, PET imaging-particularly lipid metabolism based PET with choline and acetate radioisotopes-is a useful addition to conventional imaging for biochemically recurrent prostate cancer and incorporation of PET into to the salvage treatment algorithm could potentially allow the radiation oncologist to better define extent of disease, and, with further research, may improve the therapeutic ratio of salvage radiotherapy.

\section{References}

1. Siegel RL, Miller KD, Jemal A (2015) Cancer statistics, 2015. CA Cancer J Clin 65: 5-29.

2. Cooperberg MR, Carroll PR (2015) Trends in Management for Patients With Localized Prostate Cancer, 1990-2013. JAMA 314: 80-82.

3. Bolla M, van Poppel H, Tombal B, Vekemans K, Da Pozzo L, et al. (2012) Postoperative radiotherapy after radical prostatectomy for high-risk prostate cancer: long-term results of a randomised controlled trial (EORTC trial 22911). Lancet 380: 1- 27.

4. Thompson IM, Tangen CM, Paradelo J, Lucia MS, Miller G, et al. (2009) Adjuvant radiotherapy for pathological T3NOMO prostate cancer significantly reduces risk of metastases and improves survival: long-term followup of a randomized clinical trial. J Urol 181: 956-962.

5. Wiegel T, Bartkowiak D, Bottke D, Bronner C, Steiner U, et al. (2014) Adjuvant radiotherapy versus wait-and-see after radical prostatectomy: 10-year followup of the ARO 96-02/AUO AP 09/95 trial. Eur Urol 66: 243-250.

6. Trock BJ, Han M, Freedland SJ, Humphreys EB, DeWeese TL, et al. (2008) Prostate cancer-specific survival following salvage radiotherapy vs observation in men with biochemical recurrence after radical prostatectomy. JAMA 299: 2760-2769.

7. Stephenson AJ, Scardino PT, Kattan MW, Pisansky TM, Slawin KM, et al. (2007) Predicting the outcome of salvage radiation therapy for recurrent prostate cancer after radical prostatectomy. J Clin Oncol 25: 2035-2041.

8. (2015) A Phase III Trial of Short Term Androgen Deprivation With Pelvic Lymph Node or Prostate Bed Only Radiotherapy (SPPORT) in Prostate Cancer Patients With a Rising PSA After Radical Prostatectomy.

9. (2015) A Phase III Trial of Radiation Therapy with or without Casodex in Patients with PSA Elevation Following Radical Prostatectomy for pT3NO Carcinoma of the Prostate.

10. King CR, Kapp DS (2008) Radiotherapy after prostatectomy: is the evidence for dose escalation out there? Int J Radiat Oncol Biol Phys 71: 346-350.

11. Kuban DA, Tucker SL, Dong L, Starkschall G, Huang EH, et al. (2008) Long term results of the M. D. Anderson randomized dose-escalation trial for prostate cancer. Int J Radiat Oncol Biol Phys 70: 67-74.

12. James N, Spears M, Clarke NW, Sydes M, Parker C, et al. (2014) 7540 - Impact of node status and radiotherapy on failure free survival in men with newly diagnosed non-metastatic prostate cancer: Data from $>690$ patients in the control arm of the STAMPEDE trial in ESMO Congress. Oncol 25: iv255-iv279.

13. Zagars GK, Pollack A, von Eschenbach AC (2001) Addition of radiation therapy to androgen ablation improves outcome for subclinically node-positive prostate cancer. Urology 58: 233-239.

14. Gomez P, Manoharan M, Kim SS, Soloway MS (2004) Radionuclide bone scintigraphy in patients with biochemical recurrence after radical prostatectomy: when is it indicated? BJU Int 94: 299-302.

15. Okotie OT, Aronson WJ, Wieder JA, Liao Y, Dorey F, et al. (2004) Predictors of metastatic disease in men with biochemical failure following radical prostatectomy. J Urol 171: 2260-2264.

16. Hovels AM, Heesakkers RA, Adang EM, Jager GJ, Strum S, et al. (2008) The diagnostic accuracy of CT and MRI in the staging of pelvic lymph nodes in patients with prostate cancer: a meta-analysis. Clin Radiol 63: 387-395.

17. Ackerstaff E, Pflug BR, Nelson JB, Bhujwalla ZM (2001) Detection of increased choline compounds with proton nuclear magnetic resonance spectroscopy subsequent to malignant transformation of human prostatic epithelial cells. Cancer Res 61: 3599-603.

18. Sutinen E, Nurmi M, Roivainen A, Varpula M, Tolvanen T, et al. (2004) Kinetics of [(11)C]choline uptake in prostate cancer: a PET study. Eur J Nucl Med Mol Imaging 31: 317-324. 
19. de Jong IJ, Pruim J, Elsinga PH, Vaalburg W, Mensink HJ, et al. (2003) $11 \mathrm{C}$-choline positron emission tomography for the evaluation after treatment of localized prostate cancer. Eur Urol 44: 32-38.

20. Giovacchini G, Picchio M, Coradeschi E, Bettinardi V, Gianolli L, et al. (2010) Predictive factors of $[(11) \mathrm{C}]$ choline PET/CT in patients with biochemical failure after radical prostatectomy. Eur J Nucl Med Mol Imaging 37: 301-309.

21. Husarik DB, Miralbell R, Dubs M, John H, Giger OT, et al. (2008) Evaluation of [(18)F]-choline PET/CT for staging and restaging of prostate cancer. Eur J Nucl Med Mol Imaging 35: 253-263.

22. Picchio M, Messa C, Landoni C, Gianolli L, Sironi S, et al. (2003) Value of [11C]choline-positron emission tomography for re-staging prostate cancer: a comparison with [18F]fluorodeoxyglucose-positron emission tomography. J Urol 169: 1337-1340.

23. Rinnab L, Mottaghy FM, Blumstein NM, Reske SN, Hautmann RE, et al (2007) Evaluation of [11C]-choline positron-emission/computed tomography in patients with increasing prostate-specific antigen levels after primary treatment for prostate cancer. BJU Int 100: 786-793.

24. Jadvar H, Desai B, Ji L, Conti PS, Dorff TB, et al. (2012) Prospective evaluation of $18 \mathrm{~F}-\mathrm{NaF}$ and $18 \mathrm{~F}-\mathrm{FDG}$ PET/CT in detection of occult metastatic disease in biochemical recurrence of prostate cancer. Clin Nucl Med 37: 637-643.

25. Jadvar H, Pinski J, Quinn D, Carlon L, Ye W, et al. (2009) PET/CT with FDG in metastatic prostate cancer: Castrate-sensitive vs. castrate-resistant disease. $J$ Nucl Med 50: 460

26. Effert P, Beniers AJ, Tamimi Y, Handt S, Jakse G (2004) Expression of glucose transporter 1 (Glut-1) in cell lines and clinical specimens from human prostate adenocarcinoma. Anticancer Res 24: 3057-3063.

27. Jadvar H (2009) Molecular imaging of prostate cancer with 18F-fluorodeoxyglucose PET. Nat Rev Urol 6: 317-323.

28. Murphy RC, Kawashima A, Peller PJ (2011) The utility of 11C-choline PET/ CT for imaging prostate cancer: a pictorial guide. AJR Am J Roentgenol 196: $1390-1398$.

29. Elsasser-Beile U, Wolf $P$, Gierschner D, Bühler P, Schultze-Seemann W, et al. (2006) A new generation of monoclonal and recombinant antibodies against cell-adherent prostate specific membrane antigen for diagnostic and therapeutic targeting of prostate cancer. Prostate 66: 1359-1370.

30. Rosenthal SA, Haseman MK, Polascik TJ (2001) Utility of capromab pendetide (ProstaScint) imaging in the management of prostate cancer. Tech Urol 7: 2737.

31. Troyer JK, Beckett ML, Wright GL Jr (1997) Location of prostate-specific membrane antigen in the LNCaP prostate carcinoma cell line. Prostate 30: 232-242.

32. Apolo AB, Pandit-Taskar N, Morris MJ (2008) Novel tracers and their development for the imaging of metastatic prostate cancer. J Nucl Med 49 2031-2041.

33. Swinnen JV, Roskams T, Joniau S, Van Poppel H, Oyen R, et al. (2002) Overexpression of fatty acid synthase is an early and common event in the development of prostate cancer. Int J Cancer 98: 19-22.

34. Jadvar H, Gurbuz A, Li X, Shahinian A, Conti PS, et al. (2008) Choline autoradiography of human prostate cancer xenograft: effect of castration. Mol Imaging 7: 147-152.

35. Pflug BR, Pecher SM, Brink AW, Nelson JB, Foster BA, et al. (2003) Increased fatty acid synthase expression and activity during progression of prostate cancer in the TRAMP model. Prostate 57: 245-254

36. Vavere AL, Kridel SJ, Wheeler FB, Lewis JS (2008) 1-11C-acetate as a PET radiopharmaceutical for imaging fatty acid synthase expression in prostate cancer. J Nucl Med 49: 327-334.

37. Kotzerke J, Volkmer BG, Glatting G, van den Hoff J, Gschwend JE, et al. (2003) Intraindividual comparison of [11C]acetate and [11C]choline PET for detection of metastases of prostate cancer. Nuklearmedizin 42: 25-30.

38. Hara T, Kosaka N, Kishi H (1998) PET imaging of prostate cancer using carbon11-choline. J Nucl Med 39: 990-995.

39. Price DT, Coleman RE, Liao RP, Robertson CN, Polascik TJ, et al. (2002) Comparison of [18 F]fluorocholine and [18 F]fluorodeoxyglucose for positron emission tomography of androgen dependent and androgen independent prostate cancer. J Urol 168: 273-280.
40. Oyama N, Kim J, Jones LA, Mercer NM, Engelbach JA, et al. (2002) MicroPET assessment of androgenic control of glucose and acetate uptake in the rat prostate and a prostate cancer tumor model. Nucl Med Biol 29: 783-790.

41. DeGrado TR, Coleman RE, Wang S, Baldwin SW, Orr MD, et al. (2001) Synthesis and evaluation of $18 \mathrm{~F}$-labeled choline as an oncologic tracer for positron emission tomography: initial findings in prostate cancer. Cancer Res 61: 110-117.

42. Seltzer MA, Jahan SA, Sparks R, Stout DB, Satyamurthy N, et al. (2004) Radiation dose estimates in humans for (11)C-acetate whole-body PET. J Nucl Med 45: 1233-1236.

43. Har T, Bansal A, DeGrado TR (2006) Effect of hypoxia on the uptake of [methyl$3 \mathrm{H}]$ choline, $[1-14 \mathrm{C}]$ acetate and $[18 \mathrm{~F}] \mathrm{FDG}$ in cultured prostate cancer cells. Nucl Med Biol 33: 977-984.

44. (2015) Androgen Deprivation Therapy and High Dose Radiotherapy With or Without Whole-Pelvic Radiotherapy in Unfavorable Intermediate or Favorable High Risk Prostate Cancer: A Phase III Randomized Trial.

45. Fanti S, Minozzi S, Castellucci P, Balduzzi S, Herrmann K, et al. (2015) PET/ CT with C-choline for evaluation of prostate cancer patients with biochemical recurrence: meta-analysis and critical review of available data. Eur J Nucl Med Mol Imaging 43: 55-69.

46. Umbehr MH, Müntener M, Hany T, Sulser T, Bachmann LM, et al. (2013) The role of $11 \mathrm{C}$-choline and 18F-fluorocholine positron emission tomography (PET) and PET/CT in prostate cancer: a systematic review and meta-analysis. Eur Urol 64: 106-117.

47. Mohsen B, Giorgio T, Rasoul ZS, Werner L, Ali GR, et al. (2013) Application of $\mathrm{C}$-11-acetate positron-emission tomography (PET) imaging in prostate cancer: systematic review and meta-analysis of the literature. BJU Int 112: 1062-1072.

48. Bertagna F, Abuhilal M, Bosio G, Simeone C, Rossini P, et al. (2011) Role of (1)(1)C-choline positron emission tomography/computed tomography in evaluating patients affected by prostate cancer with suspected relapse due to prostate-specific antigen elevation. Jpn J Radiol 29: 394-404

49. Reske SN, Blumstein NM, Glatting G (2008) [11C]choline PET/CT imaging in occult local relapse of prostate cancer after radical prostatectomy. Eur $\mathrm{J}$ Nucl Med Mol Imaging 35: 9-17.

50. Ceci F, Herrmann K, Castellucci P, Graziani T, Bluemel C, et al. (2014) Impact of 11C-choline PET/CT on clinical decision making in recurrent prostate cancer: results from a retrospective two-centre trial. Eur J Nucl Med Mol Imaging 41: 2222-2231.

51. Vees H, Buchegger F, Albrecht S, Khan H, Husarik D, et al. (2007) 18F-choline and/or 11C-acetate positron emission tomography: detection of residual o progressive subclinical disease at very low prostate-specific antigen values $(<1$ $\mathrm{ng} / \mathrm{mL}$ ) after radical prostatectomy BJU Int 99: 1415-1420.

52. Passoni NM, Suardi N, Abdollah F, Picchio M, Giovacchini G, et al. (2014) Utility of [11C]choline PET/CT in guiding lesion-targeted salvage therapies in patients with prostate cancer recurrence localized to a single lymph node at imaging: results from a pathologically validated series. Urol Oncol 32: 9-16.

53. Wondergem M, van der Zant FM, van der Ploeg T, Knol RJ (2013) A literature review of $18 \mathrm{~F}$-fluoride PET/CT and 18F-choline or 11C-choline PET/CT for detection of bone metastases in patients with prostate cancer. Nucl Med Commun 34: 935-945.

54. Picchio M, Spinapolice EG, Fallanca F Crivellaro C, Giovacchini G, et al. (2012) [11C]Choline PET/CT detection of bone metastases in patients with PSA progression after primary treatment for prostate cancer: comparison with bone scintigraphy. Eur J Nucl Med Mol Imaging 39: 13-26.

55. Fuccio C, Castellucci P, Schiavina R, Guidalotti PL, Gavaruzzi G, et al. (2012) Role of 11C-choline PET/CT in the re-staging of prostate cancer patients with biochemical relapse and negative results at bone scintigraphy. Eur $\mathrm{J}$ Radio 81: 893-896.

56. Evangelista L, Zattoni F, Guttilla A, Saladini G, Zattoni F, et al. (2013) Choline $\mathrm{PET}$ or PET/CT and biochemical relapse of prostate cancer: a systematic review and meta-analysis. Clin Nucl Med 38: 305-314.

57. Giovacchini G, Picchio M, Parra RG, Briganti A, Gianolli L, et al. (2012) Prostate-specific antigen velocity versus prostate-specific antigen doubling time for prediction of $11 \mathrm{C}$ choline PET/CT in prostate cancer patients with biochemical failure after radical prostatectomy. Clin Nucl Med 37: 325-331.

58. Giovacchini G, Picchio M, Parra RG, Briganti A, Gianolli L, et al. (2010) PSA 
Citation: McClinton C, Sood S, Shen X (2016) Role of Positron Emission Tomography (PET) in the Setting of Biochemically Recurrent Prostate Cancer. J Nucl Med Radiat Ther 7: 285. doi:10.4172/2155-9619.1000285

doubling time for prediction of [(11)C]choline PET/CT findings in prostate cancer patients with biochemical failure after radical prostatectomy. Eur J Nucl Med Mol Imaging 37: 1106-1116.

59. Krause BJ, Souvatzoglou M, Tuncel M, Herrmann K, Buck AK, et al. (2008) The detection rate of [11C]choline-PET/CT depends on the serum PSA-value in patients with biochemical recurrence of prostate cancer. Eur J Nucl Med Mol Imaging 35: 18-23.

60. Chondrogiannis S, Marzola MC, Ferretti A, Maffione AM, Rampin L, et al. (2013) Role of (1)(8)F-choline PET/CT in suspicion of relapse following definitive radiotherapy for prostate cancer. Eur J Nucl Med Mol Imaging 40: 1356-1364.

61. Marzola MC, Chondrogiannis S, Ferretti A, Grassetto G, Rampin L, et al. (2013) Role of $18 \mathrm{~F}$-choline PET/CT in biochemically relapsed prostate cancer after radical prostatectomy: correlation with trigger PSA, PSA velocity, PSA doubling time, and metastatic distribution. Clin Nucl Med 38: e26-e32.

62. Richter JA, Rodríguez M, Rioja J, Peñuelas I, Martí-Climent J, et al. (2010) Dual tracer 11C-choline and FDG-PET in the diagnosis of biochemical prostate cancer relapse after radical treatment. Mol Imaging Biol 12: 210-217.

63. Schillaci O, Calabria F, Tavolozza M, Caracciolo CR, Finazzi Agrò E, et al. (2012) Influence of PSA, PSA velocity and PSA doubling time on contrastenhanced $18 \mathrm{~F}$-choline PET/CT detection rate in patients with rising PSA after radical prostatectomy. Eur J Nucl Med Mol Imaging 39: 589-596.

64. Castellucci P, Fuccio C, Nanni C, Santi I, Rizzello A et al. (2009) Influence of trigger PSA and PSA kinetics on 11C-Choline PET/CT detection rate in patients with biochemical relapse after radical prostatectomy. J Nucl Med 50: 1394-400.

65. Winter A, Henke RP, Wawroschek F (2015) Targeted salvage lymphadenectomy in patients treated with radical prostatectomy with biochemical recurrence: complete biochemical response without adjuvant therapy in patients with low volume lymph node recurrence over a long-term follow-up. BMC Urol 15: 10

66. Rigatti P, Suardi N, Briganti A, Da Pozzo LF, Tutolo M, et al. (2011) Pelvic/ retroperitoneal salvage lymph node dissection for patients treated with radical prostatectomy with biochemical recurrence and nodal recurrence detected by [11C]choline positron emission tomography/computed tomography. Eur Uro 60: $935-943$

67. Karnes RJ, Murphy CR, Bergstralh EJ, DiMonte G, Cheville JC, et al. (2015) Salvage lymph node dissection for prostate cancer nodal recurrence detected by $11 \mathrm{C}$-choline positron emission tomography/computerized tomography. Urol 193: 111-116.

68. Souvatzoglou M, Krause BJ, Pürschel A, Thamm R, Schuster T, et al. (2011) Influence of (11)C-choline PET/CT on the treatment planning for salvage radiation therapy in patients with biochemical recurrence of prostate cancer. Radiother Oncol 99: 193-200.

69. Würschmidt F, Petersen C, Wahl A, Dahle J, Kretschmer M, et al. (2011) $\left.{ }^{18} \mathrm{~F}\right]$ fluoroethylcholine-PET/CT imaging for radiation treatment planning of recurrent and primary prostate cancer with dose escalation to PET/CT-positive lymph nodes. Radiat Oncol 6: 44

70. Picchio M, Berardi G, Fodor A, Busnardo E, Crivellaro CM, et al. (2014) (11) C-Choline PET/CT as a guide to radiation treatment planning of lymph-node relapses in prostate cancer patients. Eur J Nucl Med Mol Imaging 41: 12701279.

71. Casamassima F, Masi L, Menichelli C, Bonucci I, Casamassima E, et al. (2011) Efficacy of eradicative radiotherapy for limited nodal metastases detected with choline PET scan in prostate cancer patients. Tumori 97: 49-55.

72. Schick U, Jorcano S, Nouet P, Rouzaud M, Vees H, et al. (2013) Androgen deprivation and high-dose radiotherapy for oligometastatic prostate cance patients with less than five regional and/or distant metastases. Acta Oncol 52 1622-1628.

73. Supiot S, Rio E, Pacteau V, Mauboussin MH, Campion L, et al. (2015) OLIGOPELVIS - GETUG P07: a multicentre phase II trial of combined salvage radiotherapy and hormone therapy in oligometastatic pelvic node relapses of prostate cancer. BMC Cancer 15: 646. 